\title{
Strategic planning for creative enterprises
}

\author{
Andrej Kovalev ${ }^{*}$ \\ University of Economics in Bratislava, Faculty of business management, Department of Business \\ Economy, Dolnozemská cesta 1/b, 85235 Bratislava, Slovak Republic
}

\begin{abstract}
Strategic Vision and a clear definition of Business Success are vital elements of strategic planning for all creative businesses and cultural enterprises. A Vision sets out the aspirations for the future of a creative business or cultural enterprise. This Strategic Vision is the 'dream' of the future, a picture painted in words, which is intended to inspire people by appealing to the heart as well as the head. One of the leader's main functions is to inspire people towards a vision. This is 'Inspirational Leadership'. A Strategic Vision must be a Shared Vision, embraced by everyone in the business or organisation - not only the leader, the senior management team and key staff.
\end{abstract}

\section{Vision and Success}

Successful creative businesses need a combination of creative talent and strategic business management. Sometimes, one individual has both of these elements in good measure, but more often than not, the harmony of creativity and business is formed by two people, or a larger team. So, there must be a shared vision for the enterprise, even if the partners involved are very different characters with different skills. Matters of risk, growth, financial reward and lifestyle are all issues about which partners might have different views. If these are not in harmony, each person may have a valid, but different, business strategy in mind as their road map to different destinations. So the shared vision is in many ways the starting point. If people are working hard together but with different goals in mind, conflict - or at least stalemate - is likely to occur.

The process of clarifying the organisation's Vision, and definition of Success, is a crucial starting point for any business strategy or business plan. It is also useful in so far as it explores what is at the heart of the organisation, its Mission and its Values.

\section{Internal Analysis}

Classic 'SWOT Analysis' involves evaluating the Strengths and Weaknesses within a business or organisation, ie an 'Internal Analysis'. It's important to assess the strengths and weaknesses of our business, focusing particularly on strengths, especially strengths

* Corresponding author: andrej.kovalev@euba.sk 
which competitors do not have. These relative strengths are an essential element of enterprises Competitive Advantage. Business strategy is about deploying enterprises characteristics in markets and other situations where they become strengths in relation to the competition. The PRIMEFACT Checklist below provides a useful structure for a comprehensive analysis. Checklist specifically for the creative and cultural industries and have used it successfully with a range of clients including creative businesses and cultural organisations.

The PRIMEFACT checklist:

- People. What are the strengths and weaknesses of our people? Employees, directors, members, associates, advisers and other stakeholders.

- Reputation (or Brand). What is our reputation with our target customers? What are the strengths - or weaknesses - of our brand or brands?

- Intellectual Property. What intellectual property do we have? How is it protected? How easily can it be turned into income streams?

- Market Research/ Marktet Information. What information do we have about market segments and market trends? What do we know about individual clients and their specific needs?

- Ethos (or Values or Culture). What is our ethos, our values and our organisational culture? Do all stakeholders subscribe to this same ethos?

- Finances, ie money. What is the current state of profitability, cashflow and assets? How much money do we have to invest or can we borrow?

- Agility (or nimbleness or change-ability). Are we agile enough to seize new opportunities. Are people prepared to change and ready for change? Or are we unable to change?

- Collaborators (Alliances, Partnerships and Networks). What are the strengths and weaknesses of our associations with other businesses and organisations (including government)?

- Talents (competencies and skills). What are our core competencies. What skills do we have available and what gaps are there? Are we able to learn new skills?

\section{External Analysis}

All businesses and organisations operate in a changing world and are subject to forces which are more powerful than they are, and which are beyond their control. Just as a ship at sea is subject to powerful natural forces of which it needs to be aware and deal with, organisations are influenced by forces in their external business environment.

Any business strategy needs to take account of all these forces so that opportunities and threats can be identified and the organisation can navigate its way to success by matching its internal strengths to external opportunities. As an aid to identifying all these external forces, a couple of acronyms come in handy.

A PEST analysis invites enterprises to list all the relevant external forces using four headings: Political, Economic, Sociological and Technological. These are useful headings; it doesn't matter that some items might be both political and economic.

However, to look in eight rather than four directions, use the ICEDRIPS checklist: 
- Innovation including new technology and the Internet (of course) but other innovations too which may be particular to an industry.

- Competitors. Not only direct rivals but threats from substitute products, new entrants to the market, the changing power of suppliers and the changing power of customers.

- Economic factors such as inflation, exchange rates, downturns in the industry, public spending etc.

- Demographics. The relevant statistics of age, gender, geography, social class etc, and changes in these.

- Regulatory environment, ie laws, regulations, agreements and conventions.

- Infrastructure such as telecommunications networks, transport, public services and utilities.

- Partners. Strategic alliances with other companies or organisations.

- Social trends, including acceptance of technology, use of leisure time, fashions and changing beliefs.

Since the external environment in which the enterprise operates is constantly changing, the External Analysis needs to be repeated frequently and ideally constantly. In this way, the enterprise will be able to identify opportunities and threats more quickly.

\section{Competitive Advantage}

If enterprises are competing in a market place by offering the same thing as many other rivals, then enterprises can only compete on price: it's a buyer's market and prices will fall. This is the case for many creative businesses that do not succeed commercially. On the other hand, prices rise in a seller's market, with a monopoly being the strongest position to achieve in relation to customers. A profitable strategy shifts enterprises position from one of price competition towards a monopoly position. Enterprises can then raise enterprises prices. By focusing on a product or service that enterprises can deliver and rivals cannot. Yes, for that product there is a smaller demand, but enterprises are much more powerful in that particular market because there is even less supply. Our herd instinct is to follow others into bigger markets where there is more demand, but here there is also excess supply, so it's a buyer's market and prices fall.

Focusing on enterprises unique strengths and not following the crowd is counterintuitive but strategically intelligent. Enterprises difference is enterprises strength! Focus on how enterprises are different and build enterprises business around this strength. Not every potential customer will want this, but those who do will love enterprises and pay the right price. It makes perfect sense to focus on the areas in which enterprises have competitive advantage - to do only those things at which enterprises can excel in relation to competitors. In this way enterprises are competing on enterprises own terms, choosing enterprises battles, and dealing with rivals from a position of strength.

This competitive advantage may be technical, for example, expertise in a particular business area that others do not have. On the other hand, competitive advantage may derive from infrastructure, systems, logistics, or economies of scale that cannot be replicated easily by rivals. For example, wide distribution networks, detailed information about sales 
trends, production capacity or rapid delivery can provide a competitive advantage over rivals for particular businesses.

Enterprises competitive advantage may be also derived from social connections or status. It may be that enterprises are well respected in a particular community, or have connections in all the right places in a certain industry, or can relate better than rivals to a particular group of customers because of cultural, language, or other affiliations. This is especially the case in businesses where personal relationships matter. We cannot recognise where we have competitive advantage unless we analyse our competitors. This is crucial because we need to base our marketing strategy on our competitive advantage. That's to say, if we want to focus on the things we can do better than our rivals, we need to know what our rivals are good at, not so good at, and how we can outmanoeuvre them.

If enterprises are one of many supplying the market with similar products, enterprises only option is to drop enterprises prices. On the other hand, if enterprises stand out from the crowd enterprises will be in demand, and able to increase prices. It's all about supply and demand and the relationship between these two things. A large market may seem attractive, but if there's an even larger supply, then it's a buyer's market. On the other hand, a smaller market but with even fewer suppliers works to the advantage of suppliers. It's better to be a big fish in a small pond than a small fish in a big pond: small fish get eaten by bigger fish, and businesses without a competitive advantage fail.

\section{Strategic Marketing}

Strategic Marketing relates to the 'big picture' and the big decisions, such as these:

- What business should we be in?

- What do customers really want?

- At what can we excel in a competitive marketplace?

- Which customers should we decide strategically not to serve?

- What is our Unique Business Formula?

Strategic marketing involves the recognition of competition, the identification of competitive advantage and as a result, serving markets enterprises can serve better than enterprises rivals. Consequently it involves deciding which markets not to serve, because rivals can do it better. This requires both an accurate understanding of market needs, and a willingness to shape the business and its products around the needs of selected customers. Strategic Marketing is at the heart of devising a feasible Business Formula because a Business Formula has to take into account an enterprise's competitive advantage and its choices to serve some markets and not others.

In short, Strategic Marketing requires a complete change of thinking, from: 'Let's do everything we can - and try to sell to everyone' to 'Let's do only what our rivals cannot do as well as us - and sell only to those markets that want what we excel at.' Only when the big issues of marketing strategy have been decided that we can turn to the details of operational marketing. Having decided which precise markets to focus on, we can tailor our messages to the precise needs of our chosen customers. Furthermore, we can listen to customers in our chosen markets, in order to understand more fully what they really want to buy. Marketing can be described as 'looking at the enterprise from the customer's point of view'. 
In the end, Strategic Marketing is about deliberately aligning the whole enterprise to the changing needs of carefully chosen customers. This means that some markets are deliberately avoided in order to focus entirely on strategically selected markets, niches and customers. Consequently Strategic Marketing is about high level decisions about the direction of the enterprise as it manoeuvres successfully amongst competitors, uses its competitive advantage and selects particular customer groups to serve in order to fulfill its objectives and achieve its Vision.

\section{Confirmation}

This contribution is the result of the project VEGA 1/0340/19 „Podnikatel'ský rozmer subjektov kreatívneho priemyslu v kontexte inovácií a inteligentného rastu“

\section{References}

1. D. Parrish, T-shirts and Suits: A Guide to the Business of Creativity, Merseyside ACME; 2Rev Ed edition (2007)

2. D. Parrish, Chase One Rabbit: Strategic Marketing for Business Success: 63 Tips, Techniques and Tales for Creative Entrepreneurs, Wordscapes Ltd, (2014)

3. D. Hesmondhalgh, The Cultural Industries. London. SAGE Publication (2003)

4. J. Howkins, Creative Economy. Penguin Group Incorporated (2001)

5. R. Landry, M. Saïhi, Patenting and Spin-off Creation by Canadian Researchers in Engineering and Life Sciences. Journal of Technology Transfer 32, 3 (2007)

6. I. Miles, S. Gee, Innovation and Creative Places. Innovation Policy Challenges for the 21st Century. 227-243 (2013)

7. E. Munro, Building soft skills in the creative economy: Creative intermediaries, business support and the 'soft skills gap". University of Glasgow Centre Department of Theatre, Film and Television Studies, Gilmorehill Centre, Glasgow, (2017)

8. J. Potts, S. Cunningham, S. Hartey, P. Ormerod, Social network markets: A new definition of the creative industries. Journal of Cultural Economic 32, 3, 167-185 (2008)

9. D. Throsby, Economics and Culture, Cambridge University Press (2001)

https://orcid.org/0000-0001-8183-7053 